\title{
As Caras de Chernoff
}

\section{Resumo}

Trata-se de um dispositivo gráfico que representa dados multivariados para a comunicação de informações multidimensionais na forma de rostos caricaturados. É abordada a criação e evolução do método, condições para aplicação, usos, vantagens e desvantagens do processo.

\section{Abstract \\ This paper presents a graphical device with a multivaried.data as a reference for communication of multidimensional information using caricatured faces. Here are also presented the method origin and the evolution as well the conditions for application, uses, and the process' advantages and disavantages .}

A experiência dos que se dedicam a mensuração, amostragem e análise de dados, associada a inúmeras pesquisas e trabalhos teóricos, permite estabelecer hoje um conjunto de princípios que orientam a construção dos instrumentos de planejamento, reconhecimento e medida nas diversas áreas do conhecimento humano. Tais processos estatísticos consolidaram-se concomitantemente com o avanço da informática, melhorando a metodologia empregada em processos de qualificação, especificação, avaliação, sistematização e instrumentalização.

Até o advento de gráficos gerados por computador, membros da comunidade científica encontravam inúmeras dificuldades em gerar informações na forma de ícones, principalmente quando tais informações eram geradas por dados multidimensionais. Pesquisadores e membros da sociedade em geral não estavam acostumados a assimilar tais representações. Hoje, o problema é como usar os ícones para processar e representar as informações da melhor forma. Enquanto há algumas técnicas tradicionais de tratar ícones, como mapas, gráficos cartesianos, Curvas Senoidais de Andrew, Gráficos de Anderson etc., pesquisadores estão desenvolvendo novas técnicas para usar ícones na divulgação de informações.

Um dispositivo original, que usava caricaturas de rostos humanos para representar dados multivariados para a comunicação de informações multidimensionais em forma de ícones, foi proposto pelo Professor Herman Chernoff em 1973, motivado por um acordo entre o Instituto de Pesquisa Naval dos USA e a Universidade de Stanford em 1971. O Professor Chernoff considerou dados multivariados com dezoito variáveis no máximo, e permitiu representar cada variável por uma das dezoito características faciais. Uma Cara de Chernoff típica é apresentada na figura 1. T. Herbert e Davis Jr, pesquisadores do Laboratório Científico Los Alamos (LASL), em 1975 somaram a largura do nariz e orelhas circulares à face, acrescentando mais duas variáveis, conforme a figura 2. Depois deste começo, aplicações criativas evoluíram, e hoje se tornou uma ferramenta útil em análise de dados exploratória, objetivando representar os dados de forma explícita, ajudar no descobrimento de cluster, e mostrar mudanças através do tempo.

Para representar dados multivariados na forma de rostos, a variação em cada um dos parâmetros é representada através da variação em uma característica particular do rosto. Por exemplo, o primeiro componente dos dados poderia ser representado pelo comprimento do

* Mestrando em Tecnologias Aplicadas à Educação na Universidade Bandeirante de São Paulo. Bacharel e licenciado em Física pela Universidade Mackenzie/SP. Professor das Faculdades Integradas "Campos Salles". 
nariz. Outros componentes seriam representados pelos demais dezenove possíveis parâmetros, como a curvatura da boca, separação dos olhos, largura do nariz, raio das orelhas, ângulo das sobrancelhas, e assim por diante. Então, o valor global dos dados multidimensionais seria representado por um único rosto. A própria síntese da expressão das várias características individuais impressionariam o observador, constituiria uma única imagem que descreve a posição geral do ponto em seu espaço multidimensional, que combinaria várias propriedades desejáveis na comunicação visual, inclusive a integração das dimensões de exibição e a familiaridade geral dos rostos. A variedade de possibilidades de expressões faciais são praticamente infinitas. Olhando os rostos e aplicando as habilidades de processos visuais inatas nas pessoas, poderia levar um observador a criar cluster ou identificar outliers tão facilmente quanto ele nota semelhanças familiares entre pessoas, num quase inconsciente mecanismo mental, pois fomos bem adaptados e extremamente capacitados para o trabalho de reconhecimento de rostos. Conseqüentemente, seria esperado que as pessoas melhor executassem trabalhos de reconhecimento em gráficos em forma de rostos que em outros incentivos visuais comparáveis. De fato, alguma evidência sugere que a percepção dos rostos seja um processo visual especial.

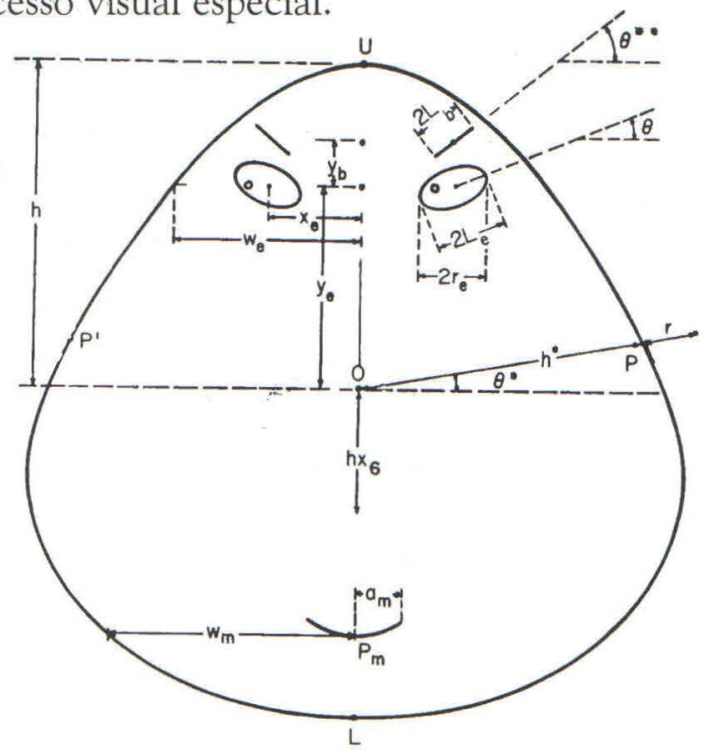

Fig 1 - Rosto original proposto por Herman Chernoff
Foram feitas várias mudanças nos rostos originais de Chernoff para estudos. $O$ nariz foi mudado de uma linha a um triângulo, e sua largura é agora uma variável adicional. A altura e largura das Caras de Chernoff foram reavaliadas levando em conta tamanho e aspecto. Havia, ainda, algumas descontinuidades e anomalias, então, pequenas mudanças nos parâmetros de esboço da cara melhoraram o aspecto final do rosto. Finalmente, foi-se reduzindo a amplitude das variações na maioria dos parâmetros, dando um aspecto mais realista aos rostos. Os parâmetros atuais foram preferidos pela comunidade científica, porque são afinados, especialmente, à variações muito pequenas em rostos "realistas".

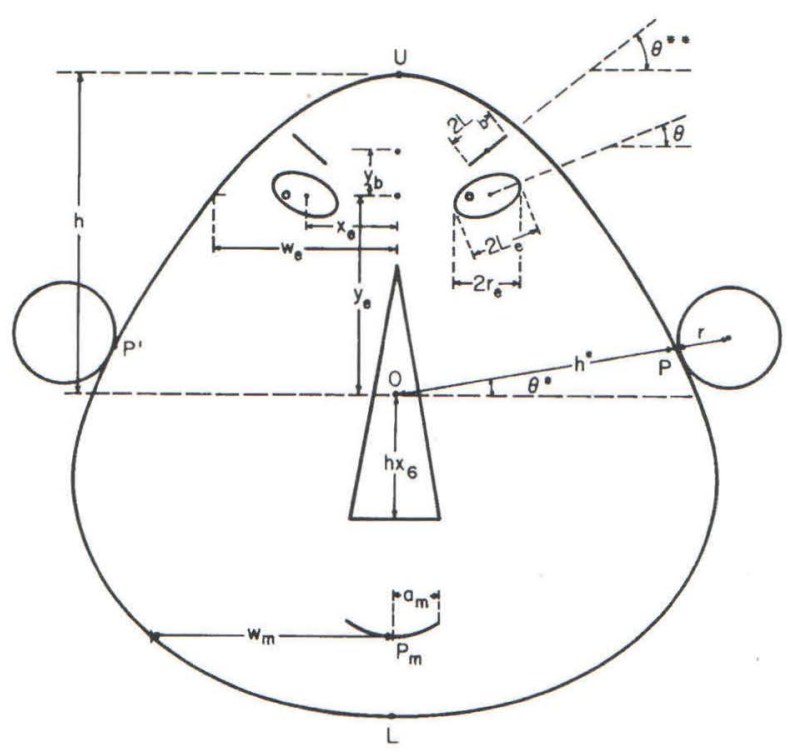

Fig 2 - Cara de Chernoff proposta por T. Herbert e Davis Jr

O pioneiro em elaborar um programa computacional para gerar as caras admitindo um vetor de respostas de 20 dimensões foi $\mathrm{J}$. Bruckner em 1978. Cada dimensão foi associada a uma das 20 características faciais. Seis características faciais estão incorporadas na construção:

(1) Cabeça. A cabeça está composta de duas elipses que se cruzam nos pontos $\mathrm{P}$ e $\mathrm{P}^{\prime}$ e orientam-se sobre eixos horizontais e verticais que atravessam a origem 0 , como ilustra a figura $1 ; \mathrm{U}$ e $L$ representam os limites verticais superiores e 
inferiores do rosto. As distâncias OU e OL são iguais e terminam na altura média do rosto (h). Os pontos de interseção, P e P', são dependentes nos valores de $\mathrm{OP} \mathrm{e}^{*}$. Estas duas variáveis combinam-se para determinar $\mathrm{P}$ e $\mathrm{P}^{\prime}$, que são simétricos sobre o eixo vertical com relação à origem $\mathrm{O}$. Portanto, a altura média do rosto é determinada pela interseção dos pontos P e P', e as excentricidades de cada elipse determinam os tamanhos e formas das elipses.

(2) Boca. A boca é um arco circular centrado no eixo vertical que passa necessariamente pelo ponto $\mathrm{Pm}$. A variável $\mathrm{X}_{8}$, pode assumir valores negativos e positivos, permitindo obter expressões "alegres" ou "tristonhas".

(3) Nariz. O nariz é um triângulo centrado à origem (ponto $\mathrm{O}$ ), com altura e largura controlada por $\mathrm{X}_{6} \mathrm{e} \mathrm{X}_{20}$.

(4) Sobrancelhas. As sobrancelhas são segmentos de reta que podem ser variados em com- primento, inclinação e posicionamento vertical pelas variáveis $\mathrm{X}_{16}, \mathrm{X}_{17}, \mathrm{e} \mathrm{X}_{18}$, respectivamente.

(5) Orelhas. As orelhas são representadas através de círculos tangentes aos pontos $\mathrm{P}$ e $\mathrm{P}^{\prime}$ cujos raios são determinados pela variável $\mathrm{X}_{19}$.

(6) Olhos. Os olhos são elipses simetricamente dispostas em relação ao eixo vertical. $\mathrm{O}$ posicionamento vertical é determinado pela variável $\mathrm{X}_{10}$, e o posicionamento horizontal é determinado pela variável $\mathrm{X}_{11}$. A variável $\mathrm{X}_{12}$, determina a inclinação, a variável $\mathrm{X}_{13}$ determina a excentricidade e a variável $\mathrm{X}_{14}$ determina o tamanho dos olhos.

A Tabela I identifica as características faciais, a amplitude de valores que cada variável pode assumir e o valor que a maioria dos programas assume automaticamente para a característica facial, quando esta não representa nenhuma dimensão de dados.

Tabela $I$

\begin{tabular}{|c|c|c|c|c|c|}
\hline $\begin{array}{c}\text { Característica } \\
\text { Facial }\end{array}$ & Variável & & Descrição & $\begin{array}{c}\text { Padrão de } \\
\text { Valores }\end{array}$ & Amplitude da Variável \\
\hline \multirow[t]{5}{*}{ Cabeça } & $X_{1}$ & controla $h *$ & $\begin{array}{l}\text { Largura da face. } \\
\text { Distância entre O e P }\end{array}$ & 0,60 & $0,20-0,70$ \\
\hline & $x_{2}$ & controla $0 *$ & $\begin{array}{c}\text { Altura da orelha. Ângulo } \\
\text { entre OP e o eixo } \\
\text { horizontal }\end{array}$ & 0,50 & $0,35-0,65$ \\
\hline & $x_{3}$ & controla $h$ & Meio da face & 0,50 & $0,50-1,00$ \\
\hline & $x_{4}$ & & $\begin{array}{c}\text { Excentricidade da elipse } \\
\text { superior da face }\end{array}$ & 0,50 & $0,50-1,00$ \\
\hline & $X_{5}$ & & $\begin{array}{l}\text { Excentricidade da elipse } \\
\text { inferior da face }\end{array}$ & 1,00 & $0,50-1,00$ \\
\hline \multirow[t]{2}{*}{ Nariz } & $X_{6}$ & controla $h X_{6}$ & Altura do nariz & 0,25 & $0,15-0,40$ \\
\hline & $X_{20}$ & & Largura do nariz & 0,10 & $0,10-0,20$ \\
\hline \multirow[t]{3}{*}{ Boca } & $x_{7}$ & controla $\mathrm{P}_{\mathrm{m}}$ & $\begin{array}{l}\text { Posição do centro da } \\
\text { boca }\end{array}$ & 0,50 & $0,20-0,40$ \\
\hline & $x_{8}$ & & Curvatura da boca & 0,00 & $-4,00-4,00$ \\
\hline & $x_{9}$ & controla $a_{m}$ & Tamanho da boca & 0,50 & $0,30-1,00$ \\
\hline \multirow[t]{6}{*}{ Olhos } & $X_{10}$ & controla $y_{e}$ & $\begin{array}{l}\text { Altura do centro dos } \\
\text { olhos }\end{array}$ & 0,10 & $0,00-0,30$ \\
\hline & $X_{11}$ & controla $x_{e}$ & Separação dos olhos & 0,70 & $0,30-0,80$ \\
\hline & $X_{12}$ & controla 0 & Inclinação dos olhos & 0,50 & $0,20-0,60$ \\
\hline & $X_{13}$ & & Excentricidade dos olhos & 0,60 & $0,40-0,80$ \\
\hline & $X_{14}$ & controla $\mathrm{Le}_{e}$ & Altura dos olhos & 0,50 & $0,20-1,00$ \\
\hline & $X_{15}$ & & $\begin{array}{c}\text { Posicionamento das } \\
\text { pupilas }\end{array}$ & 0,50 & $0,20-0,80$ \\
\hline \multirow[t]{3}{*}{ Sombrancelha } & $X_{16}$ & controla $y_{b}$ & Altura da sobrancelha & 0,80 & $0,60-1,00$ \\
\hline & $X_{17}$ & controla $0 * *$ & Ângulo da sobrancelha & 0,50 & $0,00-1,00$ \\
\hline & $X_{18}$ & & $\begin{array}{l}\text { Comprimento da } \\
\text { sobrancelha }\end{array}$ & 0,50 & $0,30-1,00$ \\
\hline Orelhas & $X_{19}$ & controla $r$ & Raio das orelhas & 0,50 & $0,10-1,00$ \\
\hline
\end{tabular}


Ao observarmos a tabela acima, podemos notar que a maioria das características faciais é controlada por uma associação de dados. Por exemplo, a verdadeira largura da face não só é uma função de $\mathrm{h}^{*}$ mas também de $0^{*}$; o tamanho da boca depende de am como também de $\mathbf{W}_{\mathrm{m}}$.

Os intervalos das variáveis foram ajustados a fim de definirem as características faciais de forma que as caras pareçam mais "humanas", e que todas as características sejam facilmente observáveis. Por exemplo, o tamanho dos olhos é fixo, o que proporciona maior visualização das pupilas; a altura da boca é fixa, para que a curvatura seja mais visível. Isto é relevante, para que todas as características sejam facilmente observáveis. Já o fato das faces possuírem características humanas é uma questão de preferência e/ou conveniência, contribuindo à interpretação de dados para algumas pessoas, e para outras não.

Para criar uma Cara de Chernoff, o primeiro passo é associar as variáveis às características faciais. Este trabalho pode ser feito de forma coincidente ou ao acaso. Alguns usuários preferem o trabalho fortuito para reduzir elementos subjetivos, outros empregam percepção de características faciais coincidentes neste trabalho. Assim, uma medida de sucesso ou fracasso pode ser associada com a curvatura da boca, e uma medida estática, fixa ou conservativa, com a posição da pupila (olhando à esquerda ou à direita).

Uma vez associadas as variáveis às características faciais, a amplitude de cada dado é determinada. Será fixado o valor atual de cada variável em escala linear ou utilizando variáveis normalizadas, na amplitude da característica facial (às vezes, é vantajoso transformar os dados em escala logarítmica ou exponencial antes de fixá-la). Já os intervalos de dados devem ser fixados cuidadosamente. Se a amplitude do intervalo fixado for muito pequena, não incluirá todos os valores de dados atuais; se for fixada demasiadamente grande, poderá ocorrer perda de discriminação na característica facial, e apresentar um resultado qualquer. A figura 3 mostra valores fixados fora dos intervalos corretos. $O$ conhecimento dos dados certamente ajudará na fixação dos parâmetros. É sugerido que se fixe a amplitude dos intervalos, conforme a tabela I, pois estudos recentes revelam que são tais amplitudes mais adequadas, tomadas hoje como uma espécie de padrão. Os softwares atuais (como o Statistic 5.1) consideram estes intervalos como padrão. Se o usuário necessitar de diferentes intervalos para uma ou mais variáveis, terá que reprogramá-las.
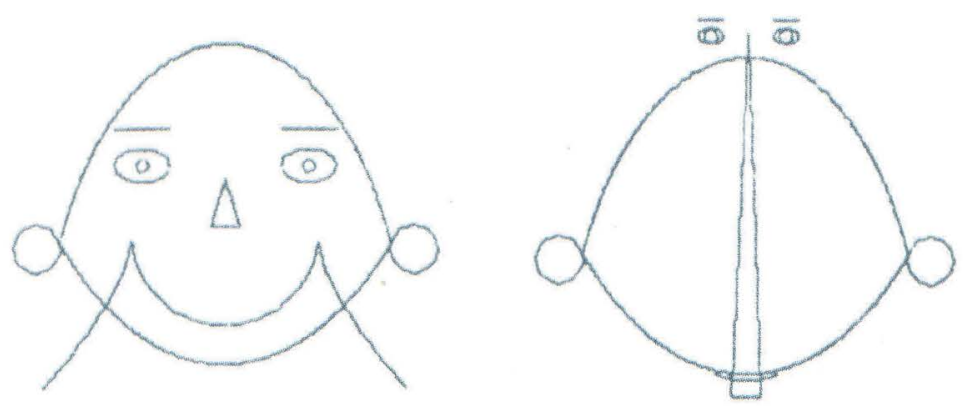

Fig 3 - Rostos gerados por parâmetros incorretos: boca (esquerda) e nariz (direita)

Para utilizar as Caras de Chernoff, devemos ter no máximo 20 variáveis, e não necessariamente todas as 20 variáveis. Quando não há variável associada a uma determinada característica facial, os elementos que compõem a matriz de dados assumirão um único valor comum a todos. Tais valores também são sugeridos na tabela I, tomados hoje como padrão e utilizados na maioria dos softwares atuais. Se o usuário necessitar de outro valor, deverá reprogramá-lo.

A figura 4 mostra como os rostos são usados para representar dados. Aqui, cada rosto representa o valor de oito variáveis de uma distribuição normal multivariada. Devemos notar que cada rosto difere significativamente dos restantes em várias características. Isto é claramente identificável quase que instantaneamente (por uma expressão facial que difere dos demais), apesar da presença considerável dos desvios em 
relação à distribuição normal (conforme exemplo do rosto 4).

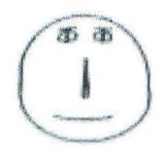

1

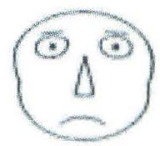

5

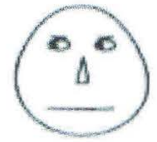

9

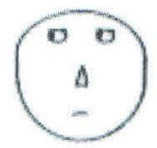

13

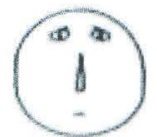

17

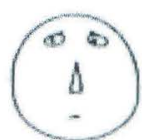

2

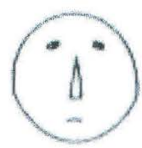

6

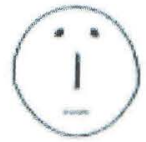

10

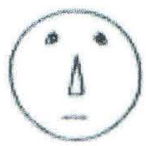

14

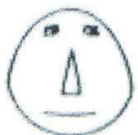

18

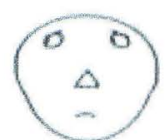

3

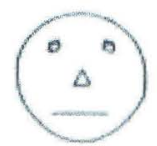

7

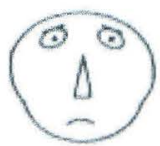

11

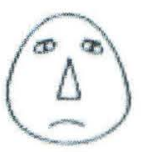

15

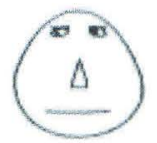

19

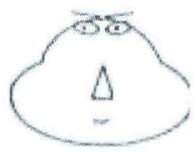

4

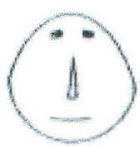

8

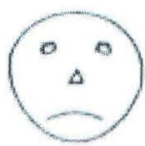

12
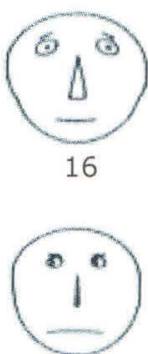

20
Fig 4

Jacob, Egeth e Bevan propuseram em 1976 uma experiência que objetivou averiguar se as pessoas poderiam executar com maior facilidade trabalhos úteis, quando os dados fossem exibidos em forma de rostos, ícones tradicionais ou exibições simbólicas. $\mathrm{O}$ trabalho consistiu num jogo de 50 pontos num espaço de nove dimensões, que seria organizado em 5 grupos. Foram gerados (num computador) 5 agrupamentos, cada um regularmente distribuido ao redor de um ponto central nomeado de protótipo. O trabalho das pessoas era olhar os 5 protótipos e alocar cada um dos 50 pontos num agrupamento pertencente a um dos 5 protótipos. As respostas corretas eram aquelas que minimizavam as distâncias euclidianas entre o ponto e o protótipo. Este é o tipo de trabalho semelhante a muitos trabalhos realistas, pois as pessoas têm os protótipos em mente e, observando um elemento novo, alocá-lo-ia num dos grupos que conhecesse. Exemplo disso, é um médico que, ao examinar os sintomas de um paciente, diagnostica a doença particular.

Os 55 pontos de dados foram representados de vários modos diferentes: (1) rostos - (2) rostos com variações reduzidas a três quartos - (3) polígonos - (4) dígitos - (5) rostos de cabeça para baixo; as pessoas executaram o mesmo trabalho com as 5 exibições. A figura 5 mostra 5 protótipos (colocados na primeira linha) e exemplos de elementos a serem associados (demais linhas) na quarta exibição diferente. Os polígonos foram usados neste teste, por serem considerados a melhor alternativa na representação gráfica da primeira experiência (Garner, 1974).
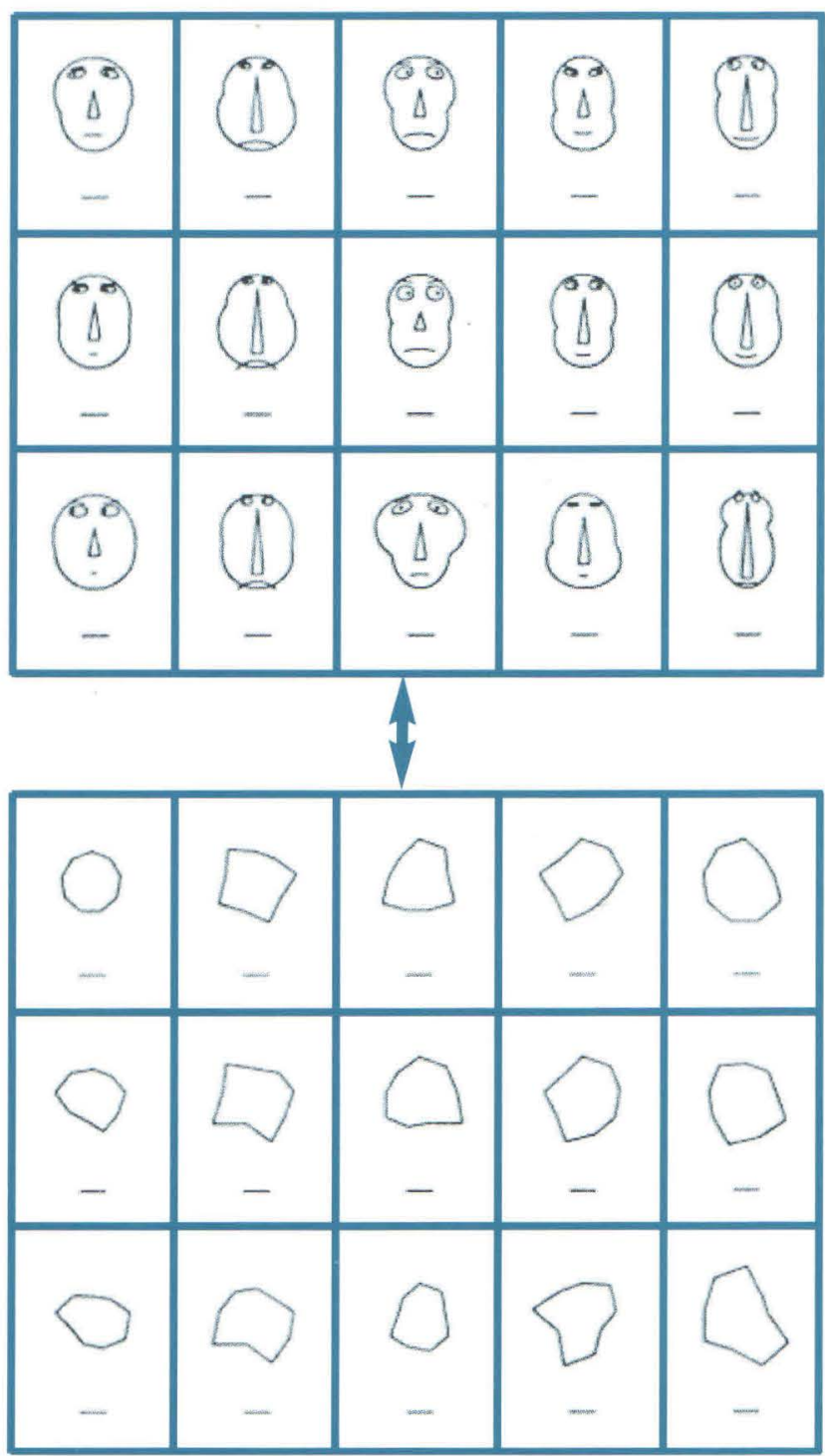


\begin{tabular}{|c|c|c|c|c|c|c|c|c|c|}
\hline 8 & & $\left(\begin{array}{c}60 \\
0\end{array}\right)$ & $\left(\begin{array}{l}3 \\
\Delta\end{array}\right)$ & & $\begin{array}{l}333 \\
333 \\
333\end{array}$ & $\begin{array}{l}363 \\
636 \\
363\end{array}$ & $\begin{array}{l}633 \\
633 \\
636\end{array}$ & $\begin{array}{l}636 \\
363 \\
366\end{array}$ & $\begin{array}{l}666 \\
666 \\
633\end{array}$ \\
\hline - & - & $\left(\begin{array}{c}0 \\
8\end{array}\right)$ & - & - & $\begin{array}{l}345 \\
214 \\
343\end{array}$ & $\begin{array}{l}374 \\
827 \\
454\end{array}$ & $\begin{array}{l}644 \\
532 \\
856\end{array}$ & $\begin{array}{l}635 \\
375 \\
556\end{array}$ & $\begin{array}{l}465 \\
586 \\
734\end{array}$ \\
\hline- & - & - & - & - & $\begin{array}{l}135 \\
123 \\
552\end{array}$ & $\begin{array}{l}345 \\
827 \\
552\end{array}$ & $\begin{array}{l}421 \\
434 \\
424\end{array}$ & $\begin{array}{l}448 \\
285 \\
146\end{array}$ & $\begin{array}{l}886 \\
748 \\
812\end{array}$ \\
\hline
\end{tabular}

Fig 5 - Acima à esquerda, rostos convencionais; acima à direita, polígonos; abaixo à direita, rostos com variações reduzidas a três quartos; abaixo, à direita, dígitos.

Os resultados levam em conta o número de erros cometidos pelas pessoas ao classificar os 50 pontos. A tabela II mostra o número médio de erros e o tempo médio gasto (em minutos).
Concluiu-se que os três tipos de rostos são claramente superiores aos polígonos e os dígitos em $\mathrm{p}$ $<0.001$.

\section{Tabela II Resultado da Experiência}

\begin{tabular}{|l|r|r|r|r|r|}
\hline & Rostos & $\begin{array}{r}\text { Rostos com variações } \\
\text { reduzidas a 3/4 }\end{array}$ & Polígonos & Dígitos & $\begin{array}{r}\text { Rostos de cabeça } \\
\text { para baixo }\end{array}$ \\
\hline Média de Erros & 15.33 & 17.08 & 27.96 & 31.88 & 24.98 \\
\hline Desvio Padrão (erros) & 5.16 & 5.76 & 4.98 & 7.30 & 6.08 \\
\hline Média de Tempo & 4.14 & 4.07 & 3.69 & 8.24 & 4.71 \\
\hline Desvio Padrão (tempo) & 1.63 & 1.46 & 1.43 & 3.22 & 1.44 \\
\hline
\end{tabular}

Não foram diagnosticadas diferenças significantes entre os dois tipos de rostos ou entre os polígonos e dígitos. Enquanto os polígonos puderam ser ordenados tão rápido quanto os rostos, eles não foram ordenados corretamente. Outra observação interessante é que os rostos convencionais eram substancialmente melhores que os rostos de ponta cabeça. Rostos de ponta cabeça têm todas as características geométricas de rostos convencionais, mas faltam-lhes a familiaridade. Eles foram incluídos para determinar se o rosto é simplesmente um design geométrico, ou se o rosto é uma exibição ímpar.

Infere-se que, neste trabalho de cunho prático, as pessoas executaram os dados representados através de rostos significativamente melhores que os dados representados por dígitos ou por uma exibição gráfica (polígonos).

Como o trabalho experimental aqui citado é razoavelmente genérico, especifica que muitos trabalhos de aplicação de dados multivariados, como o trabalho diagnosticante, o trabalho de reconhecimento de padrão, ou o trabalho de análise de agrupamento, têm como melhor forma reconhecida de representação, os rostos. Os comentários das pessoas no experimento ajudam a explicar este resultado. Eles informaram que puseram todos os "rostos felizes" em uma pilha, bravos em outra, e assim por diante; com isso, 
acharam fácil a associação. Para as outras exibições, eles informaram ter inventado estratégias mais elaboradas. De fato, para fazer as associações com rostos, as pessoas usam basicamente suas habilidades de processos visuais, enquanto outras representações demostraram requerer maior esforço mental.

Esta síntese de elementos vividos pelo observador, das várias formas da exibição facial em uma única "técnica", é uma das vantagens principais deste tipo de representação de ícones. Muitos outros tipos comuns de exibições contêm vários elementos variáveis, e poderiam ser usados para dados multivariados; mas, freqüentemente, tais exibições predispõem que deva ser analisada peça por peça, de modo seqüente no processo, que tornam obscuros o reconhecimento de relações entre elementos. Através de contrastes, os rostos induzem o observador a integrar os elementos de exibição em um todo significante. Com simples esboços ou fotografias de rostos, os observadores processam estes incentivos de forma totalmente natural, inata.

Cada uma das técnicas que representa dados multivariados tem suas vantagens e desvantagens associadas com seu uso. As Caras de Chernoff têm várias vantagens distintas sobre outras técnicas representacionais como estas apresentadas.

Primeiro, as caras são facilmente reconhecidas e descritas. Nós crescemos observando rostos e aprendendo a reconhecer expressões faciais diferentes. $\bigcirc$ Professor Chernoff estudou várias maneiras de associar variáveis a objetos, pensou em casas e carros, mas optou pelas caras pela habilidade que temos de diferenciar rostos.

Quando um rosto é apresentado a um observador, podemos confiar em uma comunalidade de idioma em nossas discussões, isto é, estamos falando de altura de nariz ou tamanho de orelha etc., e isso não gera nenhuma dupla interpretação, como em outros métodos gráficos puramente matemáticos. Tais rostos têm a vantagem de unir variáveis de dados individuais com características de figura. Porém, este encadeamento pode não ser sempre significante.

Isto conduz a uma segunda vantagem de usar as Caras de Chernoff. Nós podemos unir características faciais com o significado físico das variáveis. O sorriso pode ser usado para representar uma variável tipo " sucesso / fracasso", os olhos podem representar uma " variável estática" ou uma variável como a idade, a elipse superior que forma o rosto pode representar habilidades como era usado por Lt. Gerald Lake em um estudo no curso de pós-graduação da Escola Naval. A pesquisa da percepção de características faciais é extremamente importante e apropriada em qualquer ramo do conhecimento humano.

Alguns autores citam como desvantagem deste método a interpretação subjetiva. Mas subjetividade é totalmente ruim? Eu não penso assim, e subjetividade é a terceira vantagem de usar as Caras de Chernoff. A subjetividade é óbvia, e isto distingue a metodologia das Caras de Chernoff e de outras técnicas. Se forem usadas paralelamente as Caras de Chernoff e a técnica de "cluster hierárquicos", os agrupamentos formados serão influenciados unicamente pelas características fornecidas pela matriz de dados, eliminando assim preconceitos do receptor. $\mathrm{Da}$ mesma forma, se for usado um pacote computacional, a escolha de agrupar algoritmo não será uma escolha subjetiva.

Temos que lembrar que não há nenhum método absolutamente correto e verdadeiro, universalmente aceito para chegar a um "cluster" e representá-lo. As caras de Chernoff não estão sendo propostas como um método de chegar a decisões concludentes, mas como meio de estudar os dados.

A quarta e última vantagem de usar as Caras de Chernoff é a possibilidade de formar subconjuntos de variáveis sem fazer novamente os gráficos. Nós poderíamos querer nos concentrar nas 
variáveis associadas com os olhos e/ou orelhas e não na boca. Esta concentração é virtualmente impossível, se a pessoa usa como representação, por exemplo, a curvatura de Andrew ou um "metroglyphs".

Apesar das vantagens anteriormente citadas, o uso das Caras de Chernoff enfrenta algumas minúcias. Talvez a primeira desvantagem de usar as faces seja o dispositivo gráfico que é requerido se uma pessoa criar uma cara de Chernoff padrão. Eu digo padrão por causa de um artigo dos professores Torneiro e Tidmore, publicado em 1977 pela "American Statitical Association" em Chicago. Eles demonstraram como as caras de Chernoff podem ser impressas de forma enganosa, mudando apenas um parâmetro de impressão. Isto significa que, se criarmos um rosto padrão, este dependerá também da configuração e qualidade do equipamento usado. Se tal figura for publicada, e outras pessoas fizerem uso, o resultado será enganoso, caso os equipamentos computacionais não tenham exatamente as mesmas configurações, principalmente os parâmetros de impressão.

Uma segunda desvantagem é diagnosticada por Darrell Huff, num capítulo sobre o uso das Caras de Chernoff no artigo "Como Mentir com Estatísticas". Ele cita casos onde a amplitude dos intervalos que geram as características faciais podem ser abusivas. Porém, se recusássemos usar qualquer técnica representacional que pudesse conter alguma distorção, talvez não tivéssemos nenhuma opção.

O terceiro problema, e o mais sério que existe com este tipo de representação de dados, é a correlação embutida nas características faciais, que podem distorcer a representação de dados o bastante para causar impressões errôneas. Devemos notar que, se todas as características faciais são independentes, e não há nenhuma garantia, e de fato é bastante improvável, o rosto final será visto como uma união de 20 variáveis diferentes, independentes. Enquanto algumas das características faciais só dependem dos dados introduzidos para a variá-vel de dados correspondentes, outras características faciais estão até certo ponto correlacionadas. Por exemplo, a altura da face, as três excentricidades faciais, inclinação de olho, altura e tamanho das orelhas estão na parte superior, enquanto que as demais características estão na parte inferior; a posição da pupila só depende de outras características faciais para garantir que ela permaneça dentro do olho. Porém, a estrutura da boca depende da altura e largura do rosto, altura da orelha, excentricidade da face e comprimento do nariz, bem como dos três parâmetros da boca. A altura dos olhos depende do comprimento do nariz e altura do rosto; a separação dos olhos depende da excentricidade da face superior e altura do rosto. Estas dependências acontecem para assegurar o posicionamento formal das ca-racterísticas faciais. Os resultados das dependências podem ser equivocados. A Figura 6 mostra oito faces nas quais todos os parâmetros consi-deram constantes a altura da orelha, comprimento do nariz e a excentricidade inferior do rosto. A tabela III identifica os casos. Note o efeito destas três características faciais no comprimento da boca.

No estudo original de Chernoff, os rostos foram normalizados de forma que a altura e largura da face eram constantes. A normalização reduz as dependências, mas não as elimina, enquanto elimina também variáveis em consideração. Um exemplo disso é reduzir a altura do rosto baixando as excentricidades das elipses superiores e inferiores, bem como o comprimento do nariz, porém, perderíamos em amplitude de variáveis, que poderiam em alguns casos ser extremamente importantes. Talvez uma solução para o problema seja escolher criteriosamente as variáveis que estarão associadas às características. 


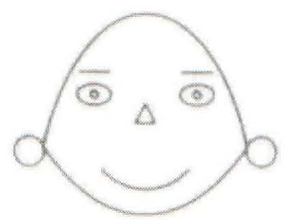

caso 1
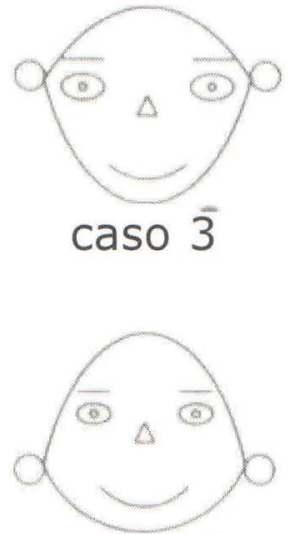

caso 5

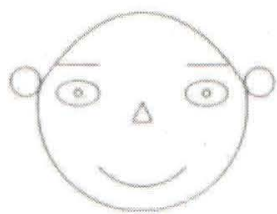

caso 7

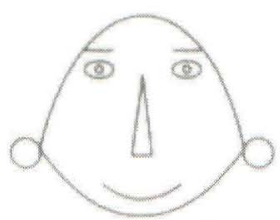

caso 2
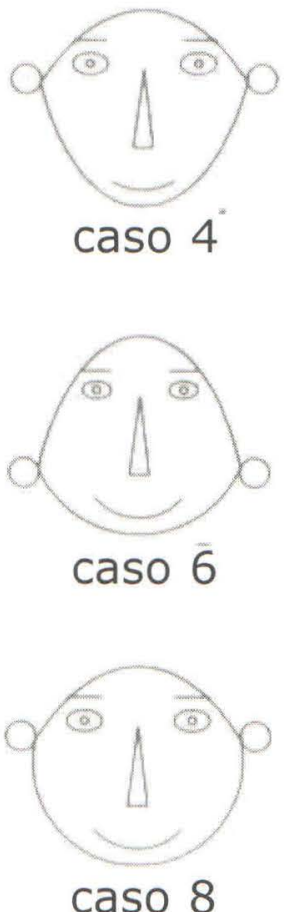

Tabela III Parâmetros de Dependência Faciais

\begin{tabular}{|c|}
\hline caso \\
\hline 1 \\
\hline 2 \\
\hline 3 \\
\hline 4 \\
\hline 5 \\
\hline 6 \\
7 \\
\hline 8 \\
\hline
\end{tabular}

\begin{tabular}{|c|}
$\begin{array}{c}\text { Comprimento } \\
\text { do nariz }\end{array}$ \\
0.15 \\
0.15 \\
0.15 \\
0.15 \\
0.40 \\
0.40 \\
0.40 \\
0.40
\end{tabular}

\begin{tabular}{|c|}
\hline $\begin{array}{c}\text { excentricidade } \\
\text { inferior }\end{array}$ \\
0.50 \\
0.50 \\
1.00 \\
1.00 \\
0.50 \\
0.50 \\
1.00 \\
1.00
\end{tabular}

\begin{tabular}{|c|}
\hline altura da orelha \\
\hline 0.35 \\
0.65 \\
0.35 \\
0.65 \\
0.35 \\
0.65 \\
0.35 \\
0.65 \\
\hline
\end{tabular}

A sugestão para se eliminar as dependências matemáticas são as regiões mostradas na figura 7 (dependências de percepção ainda podem exis- tir). Em alguns casos pode haver melhora, fixando as excentricidades superiores e inferiores do rosto em 1,00 , tornando assim o rosto circular. 


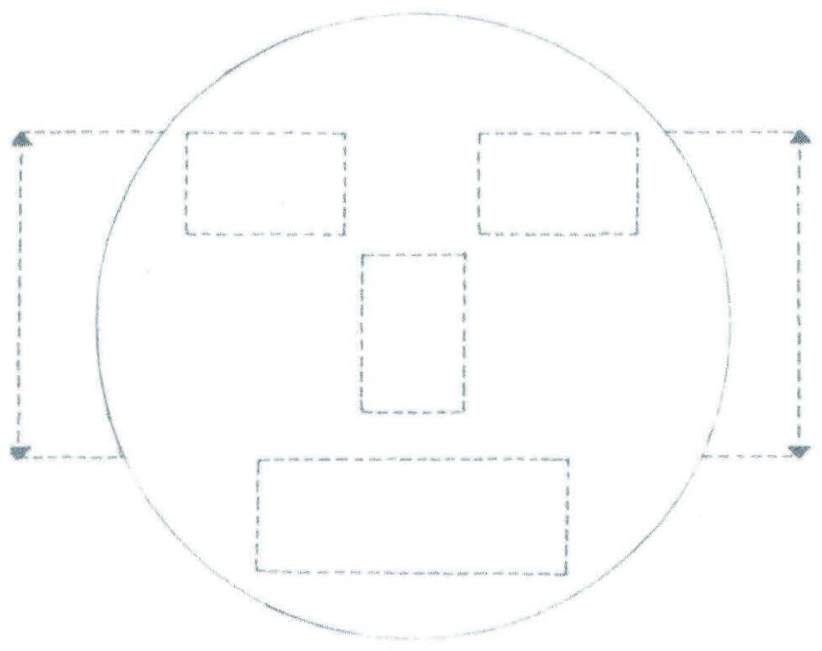

Fig 7

último ponto a ser abordado é quanto ao número de indivíduos a serem representados. Quando este número é bastante alto, o reconhecimento dos rostos, como um todo, é bastante difícil. Isto pode ser agravado se os rostos forem bastante parecidos. Vale dizer que este mesmo problema acontecerá com a maioria dos métodos representacionais.

As Caras de Chernoff é uma das várias técnicas gráficas disponíveis que exibem e analisam dados multivariados. Quando corretamente empregada, provê de informações úteis quanto à natureza dos dados, e tem vantagens importantes sobre outras técnicas gráficas. A crítica principal à técnica, sua subjetividade, pode ser considerada de fato como uma característica positiva em lugar de uma desvantagem. $\bigcirc$ problema de dependências de características faciais pode ser superado. Nos últimos anos, houve muitas aplicações interessantes das Caras de Chernoff junto com análise de "cluster", métodos de descoberta de "outlier", que estudam problemas de distribuições e análise de séries temporais. As Caras de Chernoff continuarão sendo uma ferramenta efetiva em análise de dados multivariados.

\section{REFERÊNCIAS BIBLIOGRÁFICAS}

ABRAM,G. e TREINISH, L. An Extended Data-Flow Architecture for Data Analysis and Visualization. New York : Computer

Graphics, 1995.

AHLBERG C., C. WILLIAMSON, B. SHNEIDERMAN. Dynamic Queries for Information Exploration : An Implementation And

Evaluation. New York : Chapman and Hall, 1997.

ANDERBENG, Michael R. Cluster Analysis for Appilication. New York : Academic Press, 1973.

ARNHEIM, Rudolf. Arte e Percepção Visual. 10.ed. São Paulo : Pioneira, 1996.

AUMONT, Jaques. A Imagem. São Paulo : Papirus, 1993.

CHATFIELD, Cristopher. V., COLLINS, Alexander. Introdution to Multivariate Analysis. New York : Chapman e Hall, 1992.

CHERNOFF, Herman. The Use of Faces to Represent Points in n-Dimensional. Techinical Report, Stanford, n. 71, 1971.

CLEVE, William S. Visvalizing Data. New Jersey : At \& T Bell Laboratories, 1993.

DONDIS, Donis A.. Sintaxe da Imagem Visual. São Paulo : Martins Fontes, 1991.

EVARITT, Brian. Cluster Analysis, 2.ed.. New York : Halsted Press, 1980.

GNANADESIKAN, R. Methods for Statistical Data Analysis of Multivariate Observations. New York : John Wiley \& Sons, 1997.

GOMBRICH, Ernst Hans. Arte e Ilusão. São Paulo : Martins Fontes, 1995.

HAND, D. V. Discrimination and Classification. New York : John Wiley \& Sons, 1981.

HUFF, D.. How to Lie with Statistics. New York : W. W. Norton \& Co, 1984.

KRZANOWSKI, W. V. Prenciples of Multivariate Analysis. Oxford : Clarendon Press, 1993.

LOHRDING, R. K, JOHNSON, M. M., WHITEMAN, D. E. ANNUAL SYMPOSIUM ON THE INTERFACE COMPUTER

GRAPHICS FOR EXTRACTING INFORMATION FROM DATA, 11th. Raleigh : Computer Science and Statistics, 1984.

MANLY, Bryan F. V. Muttivariate Statistical Methods. New York : Chapman and Hall, 1990.

MARDIA, K.V. KENT, V. T. BIBBY, V.M. Multivariate Analysis. London : Academic Press, 1989.

SAVILLE, David, V. WORD, Craham. Statistical Methods : The Geometric. London : Sprenger-Verlog, 1991.

SILVEY, S.D. Optimal Design. London : Champmam and Hall, 1980

TRYON, Robert C., BAILEY, MC GRAW, Daniel. Cluster Analysis. New York : Hill Book Company, 1970

SANTANNA, Porque Avaliar? : Como Avaliar?. 2.ed. Petrópolis : Vozes, 1995.

TURNER, D. W., TIDMORE, F. E.. Clustering with Chemoff-Type Faces, in: AMERICAN STATISTICAL ASSOCIATION ANNUAL MEETING,

Proceedings of the Statistics Section. Chicago : 1977.

WANG, Peter C. C. Graphical Representation of Multivariate Data. London : Academic Press, 1978. 